Case Report

\title{
Gigantomastia and Macroprolactinemia Responding to Cabergoline Treatment: A Case Report and Minireview of the Literature
}

\author{
Fatma Dilek Dellal, ${ }^{1}$ Didem Ozdemir, ${ }^{2}$ Cevdet Aydin, ${ }^{2}$ Gulfem Kaya, ${ }^{1}$ \\ Reyhan Ersoy, ${ }^{2}$ and Bekir Cakir ${ }^{2}$ \\ ${ }^{1}$ Department of Endocrinology and Metabolism, Ataturk Training and Research Hospital, 06800 Ankara, Turkey \\ ${ }^{2}$ Department of Endocrinology and Metabolism, Faculty of Medicine, Yildirim Beyazit University, 06800 Ankara, Turkey
}

Correspondence should be addressed to Fatma Dilek Dellal; drdellal@yahoo.com

Received 17 December 2015; Accepted 3 April 2016

Academic Editor: John Broom

\begin{abstract}
Copyright (C) 2016 Fatma Dilek Dellal et al. This is an open access article distributed under the Creative Commons Attribution License, which permits unrestricted use, distribution, and reproduction in any medium, provided the original work is properly cited.

Background. Macroprolactinemia is defined as predominance of high molecular weight prolactin forms in the circulation. Although macroprolactin is considered as a biologically inactive molecule, some authorities suggest treatment in symptomatic cases. Gigantomastia is defined as excess breast tissue and most cases in the literature were treated by surgical intervention. Case. A 44-year-old woman was admitted to our clinic with gigantomastia and galactorrhea. The patient had a demand for surgical therapy. In laboratory examination, she had hyperprolactinemia and macroprolactinemia. Pituitary imaging revealed $6 \mathrm{~mm}$ microadenoma in right side of the hypophysis. Since she was symptomatic, cabergolin treatment was started. Macroprolactin became negative, breast circumference decreased significantly, and galactorrhea resolved after treatment. Conclusion. Gigantomastia might be the presenting symptom in patients with macroprolactinemia. In these patients medical treatment with cabergoline may be used initially as an alternative to surgical approach.
\end{abstract}

\section{Introduction}

Prolactin (PRL) which is secreted from the pituitary gland is an essential hormone for lactation and has an important role in the development of breast tissue. It regulates lobular and acinar development by binding to cellular receptors on breast tissue and induces production of milk. Hyperprolactinemia secondary to pregnancy or dopamine antagonist treatment causes growth of breast [1]. It was shown that addition of PRL to breast tissue culture stimulates budding structures [2].

Macroprolactinemia is defined as predominance of high molecular weight PRL forms (big-big PRL, MW > $150 \mathrm{kDa}$ ) which occurs when PRL monomers form complex with antiPRL autoantibodies [3]. There are controversies about the clinical importance of macroprolactinemia, the indications for macroprolactin measurement, and the need for treatment in patients with macroprolactinemia. There is not any clinical sign that can help to differentiate macroprolactinemic patients from real hyperprolactinemic ones. Although oligomenorrhea and galactorhea are observed with less frequency in patients with macroprolactinemia, at least one of these symptoms might be seen in many patients [4]. Despite lack of any consensus about routine measurement of macroprolactin, it is recommended to determine its level in patients with asymptomatic hyperprolactinemia $[5,6]$. It is thought that macroprolactin is a biologically inactive molecule [7-9]; however some authorities suggest treatment in symptomatic cases $[3,10]$.

Gigantomastia, macromastia, and breast hypertrophy are terms used as synonym. Although there is no clear definition for gigantomastia, it is generally defined as excess breast tissue. There are various causes of gigantomastia and it can be seen in $10-25 \%$ of patients with hyperprolactinemia [11]. Patients present with gigantomastia associated physical and pshycological problems. Physical symptoms and signs are usually related to increased weight of breast tissue such as pain in shoulders, back, neck, and breast. Irritation, erythema, and ulceration under the submammarian fold 
secondary to hygienic problems might be observed [12]. Surgical interventions, hormonal therapy, or combination of these may be used for treatment. However, it is concluded by many authors that gigantomastia can not be treated medically and surgical intervention is the only option [13]. Here, we report significant clinical improvement with cabergoline treatment in a patient with gigantomastia, macroprolactinemia, and pituitary microadenoma.

\section{Case Presentation}

A 44-year-old women applied to our clinic with enlargement of breast tissue, galactorrhea, and pain in breast and back for 6 months. The patient had normal menstrual cycles and the last pregnancy was 20 years ago. She did not have any history of chronic disease, drug use, or excess weight gain. Family history was negative for breast hypertrophy. The patient had a demand for surgical therapy. In physical examination, weight was $82 \mathrm{~kg}$, height was $162 \mathrm{~cm}$, and body mass index was $31.2 \mathrm{~kg} / \mathrm{m}^{2}$.

Both breasts were hard and there was not any mass by palpation. Breast skin was tense; superficial veins were prominent and dilated. The patient did not have fever and there was not any erythema, warmth, or ulceration on breast skin. Bilateral galactorrhea was observed. The widest horizontal line passing from the areola was determined as the circumference of breast and it was $116 \mathrm{~cm}$. Serum prolactin level was $91.38 \mathrm{ng} / \mathrm{mL}(15-65 \mathrm{ng} / \mathrm{mL})$ and polyethylene glycol (PEG) preciptation for macroprolactin was positive (22.37\%). Prolactin levels before and after PEG precipitation and macroprolactin levels were shown in Figures 1 and 2, respectively. Biochemical analysis and other anterior pituitary hormone levels were normal (Table 1). Basal serum cortisol was $16.07 \mu \mathrm{g} / \mathrm{dL}$ and it was suppressed to $1.4 \mu \mathrm{g} / \mathrm{dL}$ after $1 \mathrm{mg}$ overnight dexamethasone suppression test. Serum was diluted by 1/100 for prolactin measurement to exclude "hook effect" and the result was $87.36 \mathrm{ng} / \mathrm{mL}$. In pituitary magnetic resonance imaging, a nodular lesion suggestive of a $6 \mathrm{~mm}$ microadenoma deviating the infindibulum to the left was detected in the right side of the hypophysis. Bilateral breast ultrasonography and mammography were normal.

Since the patient had galactorrhea, cabergoline treatment was started at a dose of $0.5 \mathrm{mg} /$ week. One month after the treatment, macroprolactin was negative and prolactin level was in normal limits. Breast circumference measurements made by the same clinician at the 1st, $2 \mathrm{nd}, 3 \mathrm{rd}$, and 5th months were $110,108,106$, and $105 \mathrm{~cm}$, respectively. During followup galactorrhea resolved, tenderness recovered, and breast became relaxed. The patient was satisfied with the medical treatment.

\section{Discussion}

The clinical importance of macroprolactinemia is a controversial issue for years. While it is associated with hyperprolactinemic symptoms in some studies [4, 14-16], it is reported not to cause any signs or symptoms in others $[8,11]$. This contradiction in the literature may be explained by heterogeneity

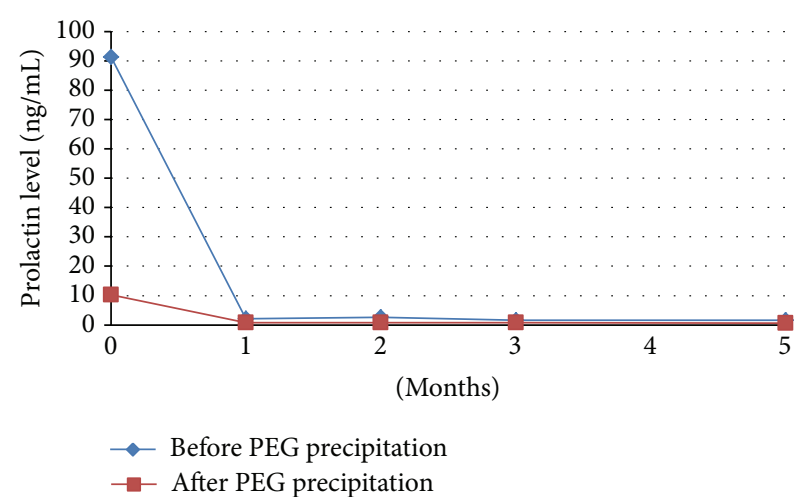

FIGURE 1: Prolactin levels before and after polyethylene glycol (PEG) precipitation.

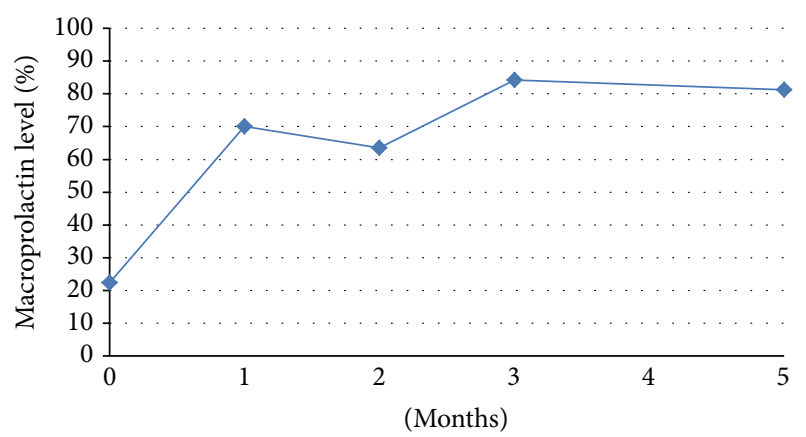

FIGURE 2: Macroprolactin levels.

in the structure of macroprolactin. Anti-PRL antibodies complexed with PRL are in the form of IgG in majority of cases; however antibodies in the form of IgA and IgM were also observed rarely [10].

Macroprolactin synthesis is generally believed to be a peripheral phenomenon. On the other hand, detection of pituitary adenoma in $20 \%$ of patients with macroprolactinemia has suggested that its origin might also be the pituitary gland. In addition, it was reported that $20 \%$ of patients with macroprolactinemia have galactorrhea and $45 \%$ have oligo/ amenorrhea [5]. However, coincidental finding of pituitary nonfunctioning adenoma and macroprolactinemia may be a cause of the oligosymptomatic clinical presentation in these patients.

There is no consensus about the definition and classification of gigantomastia and macromastia yet. These two terms are generally used for each other. In general, they are defined as development of excess breast tissue compared to normal population resulting with physical and psychological pathologies. Surgically, enlargement of breast tissue which requires $1500 \mathrm{~g}$ reduction per breast may also be described as gigantomastia [17]. In the literature, there are studies reporting different values ranging from 300 to $2000 \mathrm{~g}$ for this amount [13]. According to another definition, if the resected breast tissue is under $300 \mathrm{~g}$ it is mild, if it is between 300 and $800 \mathrm{~g}$ it is moderate, and if it is over $800 \mathrm{gr}$ it is severe macromastia [18]. Gigantomastia is classified etiologically into three main groups: idiopathic (Group 1), imbalance 
TABLE 1: Biochemical and hormonal profile of the patient.

\begin{tabular}{|c|c|c|c|c|c|}
\hline & Basal & 1st month & 2nd month & 3rd month & 5th month \\
\hline Glucose (mg/dL) & 74 & & 79 & 72 & 71 \\
\hline Creatinine $(\mathrm{mg} / \mathrm{dL})$ & 0.74 & & 0.74 & 0.78 & \\
\hline $\operatorname{ALT}(\mathrm{U} / \mathrm{L})$ & 16 & 11 & 11 & 11 & 16 \\
\hline $\mathrm{TSH}(\mu \mathrm{IU} / \mathrm{mL})$ & 1.57 & 1.53 & 2.83 & 3.03 & 2.85 \\
\hline Free T4 (ng/dL) & & & & 1.04 & 1 \\
\hline Prolactin before PEG precipitation $(\mathrm{ng} / \mathrm{mL})$ & 91.38 & 2.08 & 2.58 & 1.64 & 1.6 \\
\hline Prolactin after PEG precipitation (ng/mL) & 10.22 & 0.78 & 0.82 & 0.69 & 0.65 \\
\hline Macroprolactin (\%) & 22.37 & 70 & 63.57 & 84.15 & 81.25 \\
\hline FSH (mIU/mL) & 4.04 & & & 22.74 & \\
\hline $\mathrm{LH}(\mathrm{mIU} / \mathrm{mL})$ & 4.54 & & & 12.69 & \\
\hline Estradiol (pg/mL) & 117.8 & & & 99.83 & \\
\hline Progesterone (ng/mL) & & & & 0.55 & \\
\hline $\mathrm{GH}(\mathrm{ng} / \mathrm{mL})$ & 0.03 & & & & \\
\hline IGF-1 (ng/mL) & 115.3 & & & & \\
\hline Cortisol $(\mu \mathrm{g} / \mathrm{dL})$ & 16.07 & & & & \\
\hline ACTH (pg/mL) & 13.64 & & & & \\
\hline$\beta$-HCG $(\mathrm{mIU} / \mathrm{mL})$ & 0.1 & & & 0.1 & \\
\hline
\end{tabular}

Glucose (74-106 mg/dL), creatinine (0.5-1.2 mg/dL), ALT (0-33 U/L), TSH (0.27-4.2 $\mu \mathrm{IU} / \mathrm{mL})$, free T4 (0.9-1.7 ng/dL), prolactin (6-29.9 ng/mL), macroprolactin ( $0-40 \%$ positive, $40-60 \%$ borderline, and $>60 \%$ negative), FSH (1.7-21.5 mIU/mL), LH (1-96 mIU/mL), estradiol (12.5-498 pg/mL), progesterone $(0.1-$ $3 \mathrm{ng} / \mathrm{mL})$, GH (0-5 ng/mL), IGF-1 (94-252 ng/mL), cortisol (6.2-19.4 $\mu \mathrm{g} / \mathrm{dL})$, ACTH (0-60 pg/mL), and $\beta$-HCG $(0-5 \mathrm{mIU} / \mathrm{mL})$.

in endogenous hormone production (Group 2), and drug induced (Group 3) group. Group 1 is further devided into two: Group la includes obese patients, while Group $1 \mathrm{~b}$ includes nonobese patients. Gigantomastia cases related to pubertal period and pregnancy are classifed as Group 2a and Group 2b, respectively. Idiopathic gigantomastia has unknown etiology and insidious onset. Suggested mechanisms in Group 2a (pubertal) are increased estrogen receptors in mammary gland and hypersensitivity of receptors to estrogen and progesterone. These patients have sudden disease onset, unilateral or bilateral gigantomastia, and family history. In Group 2b (pregnancy related), possible mechanism of gigantomastia is increased sensitivity to prolactin in mammary gland. Incidence is $1 / 28000-1 / 100000$ of pregnancies, it has sudden onset and high rate of recurrence. Although possible mechanism in drug induced gigantomastia is unknown, it is commonly associated with other autoimmune diseases [13].

Generally, the first-line treatment of gigantomastia is surgery. Losing weight in Group la and withdrawal of medicine in Group 3 are the first treatment steps before surgery. Breast reduction surgery is the most frequently used surgical approach. However, recurrent surgery is required in most cases due to spontaneously continuing breast enlargement or hormonal impulses like pregnancy. In this situation total mastectomy might be an option. Hormonal treatment is generally applied before surgery, but not as a standalone option. Hormonal treatment alternatives present in the literature are bromocriptine, medroxyprogesterone, didrogesterone, tamoxifen, and danazol. Bromocriptine is effective particularly in Group 2b, while tamoxifen, medroxyprogesterone, and didrogesterone are used in Group 2a [13]. There exist no data in the literature about cabergoline treatment for gigantomastia.
In our case, coexistence of macroprolactinemia, gigantomastia, and pituitary adenoma was detected. Macroprolactinemia in the patient may be explained by three possiblities. Firstly, nonfunctioning pituitary adenoma and macroprolactinemia may be just a coincidental finding in this patient. Secondly, pituitary adenoma itself might be the origin of macroprolactin and, lastly, macroprolactin might be synthesized peripherally from breast-derivated PRL. In the literature, there is evidence that supports the first two possibilities. Leslie et al. showed monomeric PRL isoform in pituitary adenoma tissue samples of patients with macroprolactinemia. This result is supportive of the peripheral synthesis of macroprolactin [19]. Conversely, there are two studies demonstrating higher macroprolactin concentrations in adenomatous prolactinoma tissue compared to normal pituitary tissue [20]. Additionally, Lakatos et al. reported 80 -year-old male patient with intra- and parasellar pituitary mass and hyperprolactinemia largely in the form of macroprolactin [21]. These cases support the tumoral origin of macroprolactinemia. Although PRL is mainly secreted from the pituitary, studies have shown that bioactive PRL is also synthesized and secreted from adipose and glandular breast tissue [22]. In animal studies, breast-derivated PRL was shown to play an important role particularly in postpartum secretory activity [23]. Breast-derivated PRL production in our patient may also be considered an etiologic factor.

Cabergoline is an ergot derivative which has a selective, prolonged, and dose-dependent inhibitory effect on PRL. Its biological effect is regulated through dopamine, noradrenaline, and serotonin receptors. Stimulation of dopamine2 receptors in lactotrop cells causes a decline in adenylate cyclase activity by decreasing the intracellular cAMP levels. PRL exerts its proliferative effect on breast tissue via RANKL 
and IGF-2 [23]. The fact that serum PRL levels are positively correlated with breast density on mammography in postmenopausal women is put forward as an evidence of mitogenic effect of PRL on breast tissue [24]. Cabergoline causes a reduction in cell volume in prolactinoma by early inhibition of secretory mechanisms and late inhibition of gene transcription and PRL synthesis. It also reduces prolactinoma size through perivascular fibrosis and partial cell necrosis $[25,26]$. With a similar mechanism, it might cause a decrease in mitogenic activity in breast tissue and consequent reduction in size.

While coexistence of macroprolactinemia and gigantomastia was not reported in the literature previously, Oladele et al. presented 3 cases with hyperprolactinemia and gigantomastia [27]. In the first case, gigantomastia has started in pregnancy and PRL level was minimally increased. The second case was a 25-year-old nulliparous woman with minimally increased PRL levels. These two cases were not treated by dopamine agonists and underwent surgery for gigantomastia. The third patient was a 41-year-old, infertile woman who had a previous history of bromocriptine treatment. Her serum PRL level was high, other pituitary hormone levels were normal, and estradiol and progesterone levels were low. This patient was initially treated with bromocriptine and then a follow-up surgery was performed. PRL levels after surgery were not reported in all three patients. In the literature, other gigantomastia cases treated with cabergoline are all associated with pregnancy. All these patients underwent surgery after bromocriptine treatment [27]. In our case, the recovery of gigantomastia and macroprolactinemia with cabergoline treatment may be suggestive of possible role of macroprolactinemia in the etiology of gigantomastia. Whether the origin of macroprolactinemia was pituitary gland or peripheral tissue could not be identified because there was not any indication for pituitary surgery and histopathological evaluation was not made.

In conclusion, cabergoline seems to be reliable and effective option for the treatment of coexistant gigantomastia and macroprolactinemia, and it can be used as an alternative to surgery. Long term follow-up studies are required to evaluate the possibility of recurrence after withdrawal of cabergoline treatment. Although gigantomastia and macroprolactinemia are generally considered to be benign conditions, pituitary imaging, treatment with a dopamine agonist, and follow-up might be helpful in some cases.

\section{Consent}

The patient described in the case report has given informed consent for the case report to be published.

\section{Competing Interests}

The authors report no declarations of interest.

\section{References}

[1] B. M. J. Stringer, J. Rowson, and E. D. Williams, "Effect of raised serum prolactin on breast development," Journal of Anatomy, vol. 162, pp. 249-261, 1989.
[2] L. Speroni, G. S. Whitt, J. Xylas et al., "Hormonal regulation of epithelial organization in a three-dimensional breast tissue culture model," Tissue Engineering-Part C: Methods, vol. 20, no. 1, pp. 42-51, 2014.

[3] M. Kasum, S. Oreskovic, I. Zec et al., "Macroprolactinemia: new insights in hyperprolactinemia," Biochemia Medica, vol. 22, no. 2, pp. 171-179, 2012.

[4] A. Alfonso, K. I. Rieniets, and R. A. Vigersky, "Incidence and clinical significance of elevated macroprolactin levels in patients with hyperprolactinemia," Endocrine Practice, vol. 12, no. 3, pp. 275-280, 2006.

[5] S. Melmed, F. F. Casanueva, A. R. Hoffman et al., "Diagnosis and treatment of hyperprolactinemia: an endocrine society clinical practice guideline," Journal of Clinical Endocrinology and Metabolism, vol. 96, no. 2, pp. 273-288, 2011.

[6] L. Vilar, M. Fleseriu, and M. D. Bronstein, "Challenges and pitfalls in the diagnosis of hyperprolactinemia," Arquivos Brasileiros de Endocrinologia e Metabologia, vol. 58, no. 1, pp. 922, 2014.

[7] F. A. Jamaluddin, P. Sthaneshwar, Z. Hussein, N. Othman, and S. P. Chan, "Importance of screening for macroprolactin in all hyperprolactinaemic sera," Malaysian Journal of Pathology, vol. 35, no. 1, pp. 59-63, 2013.

[8] R. Vaishya, R. Gupta, and S. Arora, "Macroprolactin; a frequent cause of misdiagnosed hyperprolactinemia in clinical practice," Journal of Reproduction \& Infertility, vol. 11, no. 3, pp. 161-167, 2010.

[9] F. A. Cattaneo and M. N. Fahie-Wilson, "Concomitant occurrence of macroprolactin, exercise-induced amenorrhea, and a pituitary lesion: a diagnostic pitfall. Case report," Journal of Neurosurgery, vol. 95, no. 2, pp. 334-337, 2001.

[10] A. Elenkova, Z. Abadzhieva, N. Genov, V. Vasilev, G. Kirilov, and S. Zacharieva, "Macroprolactinemia in a patient with invasive macroprolactinoma: a case report and minireview," Case Reports in Endocrinology, vol. 2013, Article ID 634349, 5 pages, 2013.

[11] A. Shimatsu and N. Hattori, "Macroprolactinemia: diagnostic, clinical, and pathogenic significance," Clinical and Developmental Immunology, vol. 2012, Article ID 167132, 7 pages, 2012.

[12] G. A. Rahman, I. A. Adigun, and I. F. Yusuf, "Macromastia: a review of presentation and management," The Nigerian Postgraduate Medical Journal, vol. 17, no. 1, pp. 45-49, 2010.

[13] A. Dancey, M. Khan, J. Dawson, and F. Peart, "Gigantomastiaa classification and review of the literature," Journal of Plastic, Reconstructive and Aesthetic Surgery, vol. 61, no. 5, pp. 493-502, 2008.

[14] S. Vallette-Kasic, I. Morange-Ramos, A. Selim et al., "Macroprolactinemia revisited: a study on 106 patients," Journal of Clinical Endocrinology and Metabolism, vol. 87, no. 2, pp. 581-588, 2002.

[15] J. Gibney, T. P. Smith, and T. J. McKenna, “The impact on clinical practice of routine screening for macroprolactin," Journal of Clinical Endocrinology and Metabolism, vol. 90, no. 7, pp. 39273932, 2005.

[16] M. Taghavi and F. Sedigheh, "Macroprolactinemia in patients presenting with hyperandrogenic symptoms and hyperprolactinemia," International Journal of Endocrinology and Metabolism, vol. 6, no. 3, pp. 140-143, 2008.

[17] A. Gliosci and F. Presutti, "Virginal gigantomastia: validity of combined surgical and hormonal treatments," Aesthetic Plastic Surgery, vol. 17, no. 1, pp. 61-65, 1993. 
[18] F. R. Grippaudo, D. C. Kennedy, P. Tiwari, F. Talavera, S. M. Shenaq, and N. G. Slenkovich, "Liposuction only breast reduction," eMedicine.com, July 2009, http://emedicine.medscape .com/article/1276259.

[19] H. Leslie, C. H. Courtney, P. M. Bell et al., "Laboratory and clinical experience in 55 patients with macroprolactinemia identified by a simple polyethylene glycol precipitation method," Journal of Clinical Endocrinology and Metabolism, vol. 86, no. 6, pp. 2743-2746, 2001.

[20] C. Mounier, J. Trouillas, B. Claustrat, R. Duthel, and B. Estour, "Macroprolactinaemia associated with prolactin adenoma," Human Reproduction, vol. 18, no. 4, pp. 853-857, 2003.

[21] G. Lakatos, N. Szücs, Z. Kender, S. Czirják, and K. Rácz, "Macroprolactinemia associated with pituitary macroadenoma: treatment with quinagolide," Orvosi Hetilap, vol. 151, no. 26, pp. 1072-1075, 2010.

[22] M. Zinger, M. McFarland, and N. Ben-Jonathan, "Prolactin expression and secretion by human breast glandular and adipose tissue explants," Journal of Clinical Endocrinology and Metabolism, vol. 88, no. 2, pp. 689-696, 2003.

[23] N. D. Horseman and K. A. Gregerson, "Prolactin actions," Journal of Molecular Endocrinology, vol. 52, no. 1, pp. R95-R106, 2013.

[24] G. A. Greendale, M.-H. Huang, G. Ursin et al., "Serum prolactin levels are positively associated with mammographic density in postmenopausal women," Breast Cancer Research and Treatment, vol. 105, no. 3, pp. 337-346, 2007.

[25] J. S. Bevan, J. Webster, C. W. Burke, and M. F. Scanlon, "Dopamine agonists and pituitary tumor shrinkage," Endocrine Reviews, vol. 13, no. 2, pp. 220-240, 1992.

[26] P. G. Crosignani and C. Ferrari, "2 Dopaminergic treatments for hyperprolactinaemia," Bailliere's Clinical Obstetrics and Gynaecology, vol. 4, no. 3, pp. 441-455, 1990.

[27] A. O. Oladele, J. K. Olabanji, and G. H. Alabi, "Reduction mammoplasty: the experience in Ile-Ife, Nigeria," Nigerian Journal of Medicine, vol. 16, no. 3, pp. 261-267, 2007. 


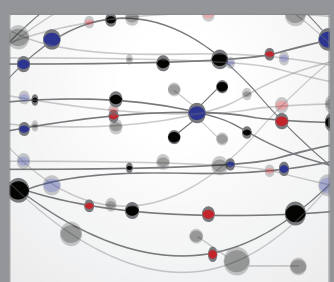

The Scientific World Journal
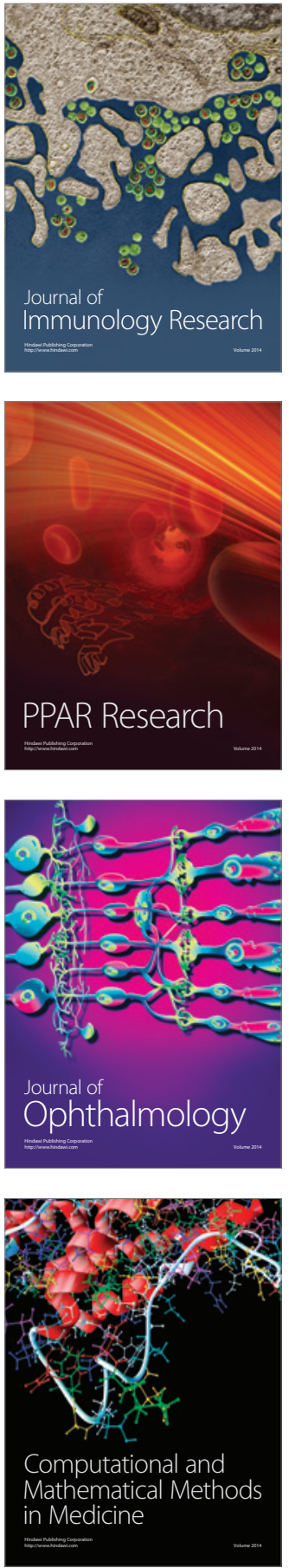

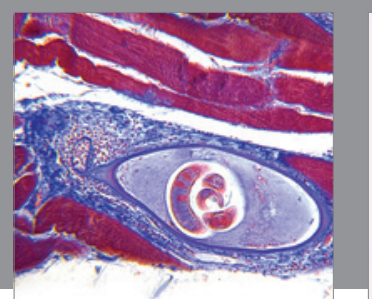

Gastroenterology Research and Practice

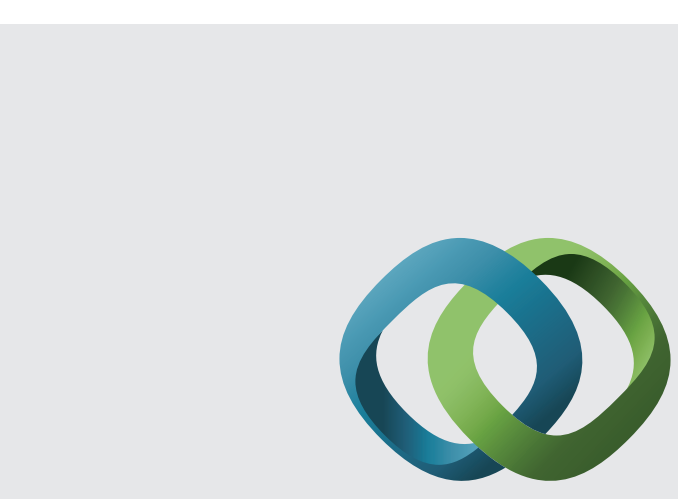

\section{Hindawi}

Submit your manuscripts at

http://www.hindawi.com
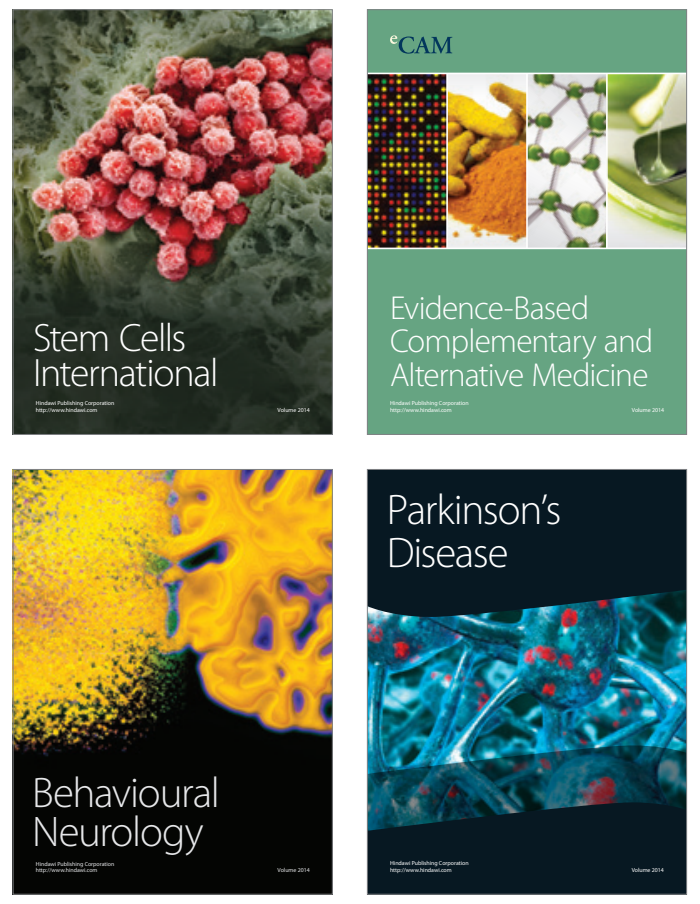
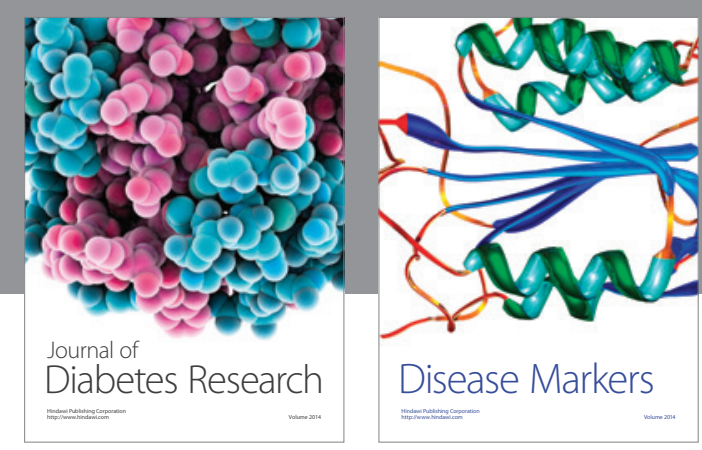

Disease Markers
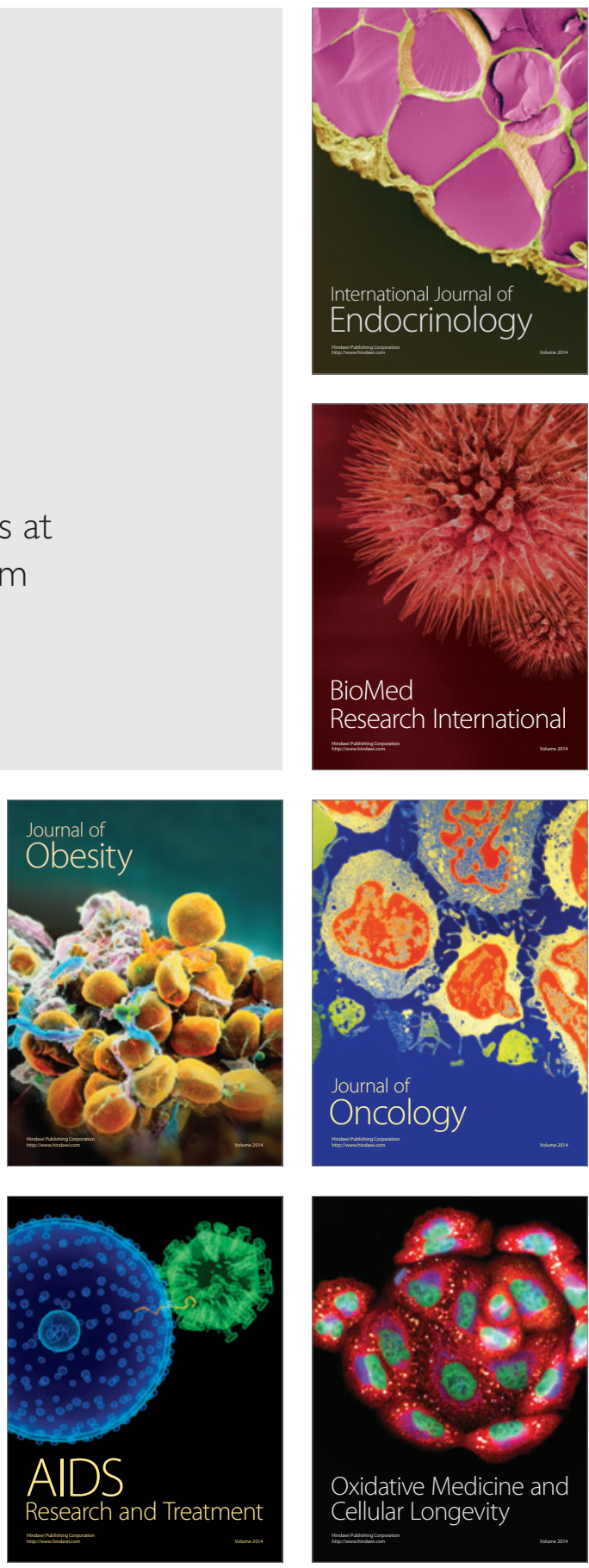